\title{
Serebral palside yürüme analizi
}

\author{
Gait analysis in cerebral palsy
}

\author{
Avni illhan Bayhan \\ T.C. Sağlık Bakanlığı, Metin Sabancı Baltalimanı Kemik Hastalıkları Eğitim ve Araştırma Hastanesi, İstanbul
}

Serebral palsi, hastalığın şiddeti ve hareket kusurlarının tiplerine göre farklılık gösteren, birçok yürüme modelinin bir arada gözlenebildiği bir hastalık grubudur. Klinik yürüme analizi, yürümedeki sapmaların, objektif ve sayısal değerlendirilmesinde, klinisyenlerin tedavi planlamasında ve hastaların tedavi sonrası değerlendirilmesinde kullanılan bir yöntemdir. Bu derlemenin amacı serebral palside sık gözlenen yürüme bozukluklarını tanımlamak ve klinik yürüme analizinde saptanan değişiklikleri özetlemektir.

Anahtar sözcükler: yürüme analizi; serebral palsi
Cerebral palsy is a group of disease in which several kinds of gait deviations can be observed, varying according to the disease severity and movement disorder. Clinical gait analysis is an essential tool for objective and quantitative evaluation of gait deviations, for clinicians in treatment planning, and for the assessment of treatment outcomes. The aim of this review is to describe the common gait patterns in cerebral palsy, and summarize the gait deviations that can be detected with gait analysis.

Key words: gait analysis; cerebral palsy erebral palsi (SP) terimi, progresif olmayan; fakat zamanla değişen, gelişimin erken basamaklarında beyinde oluşan anomali veya lezyonlara sekonder gelişen, hareket bozukluğu sendromları olarak tanımlanabilir. Avrupa'da prevalansı son 30 yılda değişmemekle birlikte, her bin canlı doğumda 1,5 ile 3 arasında gözlenmektedir. ${ }^{[1]}$ Ülkemizde bu oran, Serdaroğlu ve ark.'nın yaptığı çalışmada her bin canIı doğumda 4,4 olarak saptanmıştır. ${ }^{[2]}$ SP'de gelişen birincil sorunlar kas spastisitesi, kas gücü zayıflığı ve azalmış selektif motor kontrol olup, sekonder olarak kas kontraktürleri ve kemik deformiteleri gelişir. SP'li olgularda gelişen nöromotor kısıtlılıklar, postür ve yürüme gibi hareket aktivitelerinde sınırlanmalara neden olur. SP'li olguların \%75'i ambulatuvardır. ${ }^{[3]}$ Serebral palsi grubunda, hastalığın şiddeti ve hareket kusurlarının tipleri farklılık gösterir. Klinik sınıflandırma, hareket kusurlarının topografik özelliklerine göre (hemiplejik, diplejik, kuadriplejik, ataksik veya mikst) veya kaba motor fonksiyonel sınıflandırma sistemi ile fonksiyonel kapasitenin durumuna göre yapılabilmektedir. ${ }^{[4]}$

Yürüme, iskelet ve nöromotor sistemlerin etkileşiminin dinamik bir sonucudur. Bu sistemlerde, serebral palsi gibi rahatsızlıkların yarattığı disfonksiyonlara sekonder yürüme bozukluğu gelişebilir. Yürüme analizi değerlendirmesi, yalnız yürüme bozukluklarının tanısının konmasında değil, aynı zamanda tedavinin planlanmasında da yardımcı olmaktadır. Yürüme analizi sayesinde elde edilen sayısal bilgiler, klinisyenlerin cerrahi tedavi (osteotomi, tendon uzatma/transfer/ gevşetme), ton ayarlaması, fizik tedavi, uygun ortez veya protez seçimi konusunda karar vermesinde yardımci olur. ${ }^{[5]}$

Perry'e göre patolojik yürüyüş, sıklıkla normal yürümenin sağlanmasında önemli olan aşağıdaki beş ana şartın kaybolması sonucu oluşmaktadır:

1- Basma fazında stabilitenin sağlanması.

2- Salınım fazında ayağın yerden olan yeterli uzaklığının sağlanması.

3- Salınım sonu fazda ayağın uygun ön pozisyonunun sağlanması.

4- Yeterli adım mesafesinin sağlanması.

5- Enerji korunması. ${ }^{[6]}$

- Illetişim adresi: Doç. Dr. Avni İlhan Bayhan, Metin Sabancı Baltalimanı Kemik Hastalıkları Eğitim ve Araştırma Hastanesi, Rumeli Hisarı Sok. No: 62, Baltalimanı, Sarıer, İstanbul Tel: 0212 - 3237075 e-posta: ilhanbayhan@hotmail.com

- Geliș tarihi: 1 Ekim $2018 \quad$ Kabul tarihi: 1 Ekim 2018 
Moissenet ve Armand'a göre kompleks yürüme bozukluğu olan olguların değerlendirmesinde basit bir algoritma kullanılabilir. ${ }^{[7,8]}$ Bu algoritma üç basamaktan oluşmaktadır:

1- Yürüme farklılığının ortaya konması.

2- Yürüme farklıığının anlaşılması ve klinik bulgularla ilişkilendirilmesi.

3- En uygun tedavi yönteminin ortaya konması.

Bu derlemenin amacı, yürümenin ve yürüme bozukluğunun değerlendirilmesinde kullanılan metodların ve SP'li olgularda gözlenen yürüme modellerinin ve sapmalarının tanımlanmasıdır.

\section{KLINIK YÜRÜME ANALIZi (KYA)}

Klinik yürüme analizi, hastanın yürüme şeklindeki farklılıkları ve bunun nedenlerini araştırmayı sağlar. KYA sırasında hastaların yürüme karakterlerini içeren çok sayıda sayısal veri toplanır ve analiz edilir.

Yürüme analizi değerlendirmesi laboratuvarlar arasında küçük farklılıklar göstermekle birlikte kabaca beş başlık altında incelenebilir:
1- Görsel yürüme analizi.

2- Klinik muayene.

3- Üç boyutlu bilgisayarlı yürüme analizi.

4- Ayak basınç verileri.

5- Enerji tüketimi.

\section{Görsel Yürüme Analizi}

Yürümenin değerlendirilmesi görsel yürüme analizi ile başlar. Sagittal planda, basma fazında ayağın yere temas etmesi ile başlanan değerlendirme diz, kalça ve son olarak pelvisin eklem hareketlerinin değerlendirilmesi ile son bulur. Bu gözlem sırası pelvisden ayağa doğru da yapılabilir. Benzer sırada değerlendirmeye koronal ve transvers planlarda da devam edilir. Bu şekilde önce basma fazı problemleri ortaya konur ve ardından salınım fazı değerlendirilir. Yürümedeki tüm farklılıklar not edilir (Tablo 1). ${ }^{[5]}$ Görsel yürüme analizi ile daha objektif değerlendirme yapabilmek için çeşitli görsel yürüme değerlendirme araçları geliştirilmiştir. Bunların en bilinenleri şunlardır:

Tablo 1. Gözlemsel yürüme analizi

\begin{tabular}{|c|c|c|c|}
\hline & Sagittal Plan Gözlemi & Koronal Plan Gözlemi & Transvers Plan gözlemi \\
\hline \multicolumn{4}{|l|}{ Basma Fazı } \\
\hline Ayak/Ayak Bileği & $\begin{array}{l}\text { Ayak Temas Tipi: } \\
\text { Topuk-ayak önü } \\
\text { Tüm taban } \\
\text { Ayak önü-topuk } \\
\text { Ayak önü-ayak önü }\end{array}$ & $\begin{array}{l}\text { Ayak Pozisyonu: } \\
\text { Normal } \\
\text { Varus } \\
\text { Valgus }\end{array}$ & $\begin{array}{l}\text { Ayak Ilerleme Açısı: } \\
\text { Normal } \\
\text { Internal } \\
\text { Eksternal }\end{array}$ \\
\hline Diz & $\begin{array}{l}\text { Diz Pozisyonu: } \\
\text { Normal } \\
\text { Fleksiyonda } \\
\text { Hiperekstansiyonda }\end{array}$ & $\begin{array}{l}\text { Diz Pozisyonu: } \\
\text { Normal } \\
\text { Varus } \\
\text { Valgus }\end{array}$ & $\begin{array}{l}\text { Diz Pozisyonu: } \\
\text { Normal } \\
\text { Internal } \\
\text { Eksternal }\end{array}$ \\
\hline Kalça/Pelvis & $\begin{array}{l}\text { Kalça/Pelvis Pozisyonu* } \\
\text { Normal } \\
\text { Anterior Tilt } \\
\text { Posterior Tilt }\end{array}$ & $\begin{array}{l}\text { Kalça/Pelvis Pozisyonu* } \\
\text { Normal } \\
\text { Abduksiyon } \\
\text { Adduksiyon }\end{array}$ & $\begin{array}{l}\text { Kalça/Pelvis Pozisyonu* } \\
\text { Normal } \\
\text { İnternal } \\
\text { Eksternal }\end{array}$ \\
\hline \multicolumn{4}{|l|}{ Salınım Fazı } \\
\hline Ayak/Ayak Bileği & $\begin{array}{l}\text { Ayak Pozisyonu: } \\
\text { Normal } \\
\text { Düşük ayak* }\end{array}$ & & \\
\hline Diz & $\begin{array}{l}\text { Diz Pozisyonu: } \\
\text { Normal } \\
\text { Sert diz* } \\
\text { Hiperekstansiyon }\end{array}$ & & \\
\hline Kalça/Pelvis & & $\begin{array}{l}\text { Kalça/Pelvis } \\
\text { Normal } \\
\text { Makaslama }\end{array}$ & \\
\hline
\end{tabular}

* Yalnız gözlemsel olarak değerlendirilmesi zor olanlar 
1- Observational Gait Scale. ${ }^{[9]}$

2- Visual Gait Score. ${ }^{[10]}$

3- Salford Gait Tool.[11]

4- Edinburgh Visual Gait Scale. ${ }^{[12]}$

5- Observational Gait Analysis. ${ }^{[13]}$

6- Physician Rating Scale. ${ }^{[14]}$

\section{7- Visual Gait Assessment Scale. ${ }^{[15]}$}

Rathinam ve ark.'nın yaptığı sistematik derlemede, güvenilirliği ve geçerliliği en yüksek olan görsel değerlendirme metodu Edinburgh Visual Gait Scale olarak saptanmasına rağmen, metodların hiçbiri bilgisayarlı yürüme analizi kadar tutarlı bulunamamıştır. ${ }^{[16]}$

\section{Klinik Muayene}

SP'li çocukların fizik muayenesinde, özellikle görsel analiz sırasında yürüme şeklinde değişikliğe neden olabilecek yapısal bozuklukların ortaya konmasına dikkat edilir. Bu amaçla eklem hareket açıklığı, manuel kas gücü[ ${ }^{[17]}$, kas tonusu (Modifiye Ashworth Skalası) ${ }^{[18]}$, motor kontrol/seçicilik, kemik dizilimi değerlendirmesi yapılır ve fonksiyonel kapasite skorlamaları kayıt edilir (Kaba Motor Fonksiyonel Skorlama ${ }^{[4]}$, Fonksiyonel Mobilite Skorlaması ${ }^{[19]}$ vb.).

\section{Üç Boyutlu Yürüme Analizi}

Klinik muayene, görsel analizde saptanan patolojilerin nedenlerinin anlaşılmasında önemli yer alsa da statik bir değerlendirme olarak kalmaktadır. Eklem hareketlerinin dinamik ölçümleri (kinematik ve kinetik) ancak üç boyutlu yürüme analizi ile yapılabilir. Örneğin; kas gücü değerlendirmesi elle veya cihaz desteğiyle yapılabilir, fakat bu değerlendirme kasın yürüme sırasındaki fonksiyonel aktivitesi ile uyumlu olduğu anlamına gelmeyebilir. Görsel yürüme analizi değerlendirmesi kinematik veriler (eklem hareket açıklığı) hakkında fikir vermekle birlikte sübjektif olması nedeniyle gözlemcinin bilgi ve tecrübesine bağımlıdır. Ayrıca, görsel yürüme analizi kinetik veriler (güç, moment) hakkında sınırlı bilgi verir. Bunun aksine, üç boyutlu yürüme analizi sayesinde daha ayrıntılı, ölçülebilir bilgi elde edilebilir ve yürümede farklılığa yol açan birincil, ikincil ve kompansatuvar değişiklikler net bir şekilde ortaya konabilir. ${ }^{[5]}$

Üç boyutlu yürüme analizi, eklem aksı ile uyumlu belirli anatomik noktalara yerleştirilen işaret cihazlarının (markırların) birçok farklı açıdaki kameralarla, aktif veya pasif optik hareket yakalama sistemi ile yürüme verilerinin bilgisayarlı ortama aktarılmasına dayanmaktadır. íki veya daha fazla kamera tarafından işaret cihazlarının algılanması, otomatik dijitasyon tekniği ile, gerçek zamanlı ve $1 \mathrm{~mm}$ 'lik doğrulukla üç boyutlu koordinatların oluşturulmasını sağlar. ${ }^{[20]}$ Biyomekanik modellemeler kullanılarak, bu koordinatlar aracılığıyla vücut segmentlerinin ve eklem merkezlerinin, doğrusal ve açısal deplasmanı, hız ve ivmelenmesi hesaplanabilir. Klinik değerlendirmede kullanılmak üzere birçok farkI biyomekanik model (Shriner Hospital, Newington Hospital, Helen Hayes Hospital vb.) geliştirilmiştir.

Biyomekanik modellemeler sonucunda, ilk önce yürüme döngüsü boyunca oluşturulan zaman ve mesafe parametreleri elde edilir (Tablo 2). Ardından, eklemlerin üç boyutta oluşturdukları açısal değişkenler kinematik veriler olarak toplanır. Sagittal plan fleksiyon-ekstansiyon hareketini, frontal plan adduksiyon-abduksiyon hareketini ve transvers plan iç-dış rotasyon hareketini göstermektedir (Şekil 1). Kinematik verilere dayanarak, Gait Profile Score, Movement Analysis Profile ${ }^{[21]}$ veya Gait Deviation Index ${ }^{[22]}$ gibi yürüme skorlamaları hesaplanabilir. Dinamik veya kinetik veri, yürüme sırasında hastanın oluşturduğu kuvvetleri tanımlar. ${ }^{[23]}$ Kinetik veriler, her eklem için yer tepkime kuvvetlerine, eklem momentlerine ve eklem güçlerine denk gelmektedir. Bu verilerin hesaplanması için, kuvvet plaklarından basma fazı boyunca elde edilen yer tepkime vektörü ve kinematik veriler birleştirilerek, zıt dinamik kullanılmakta ve yürüme boyunca her eklemin oluşturduğu moment ve güç eğrileri elde edilmektedir (Şekil 2 ve 3 ).

Yürüme analizinde yapılan eş zamanlı elektromiyografi (EMG) ile, kas aktivitesinin zamanı ve yoğunluğu değerlendirilebilir. Böylece, kasın aktivite zamanı (gecikmiş, yetersiz veya uzamış aktivite), ko-kontraksiyon dönemi ve yürüme sırasındaki kas spastisitesi hakkında bilgi edinilir. ${ }^{[24]}$ Klinik yürüme analizinde SENIAM (surface EMG for non-invasive assessment of muscles)'in önerdiği spesifik prosedürlerle genellikle yüzey elektrodları kullanılır. ${ }^{[25]}$

Tablo 2. Yürümenin zaman-mesafe parametreleri

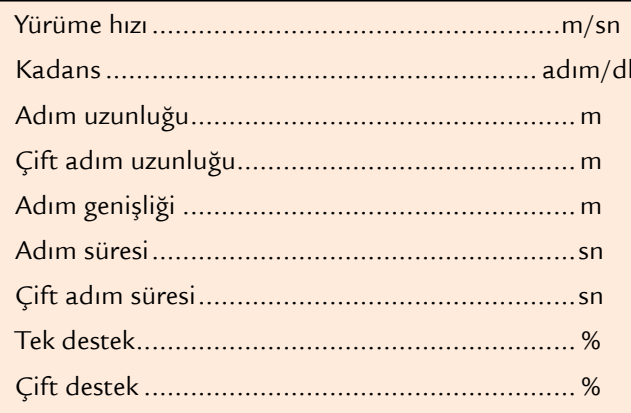



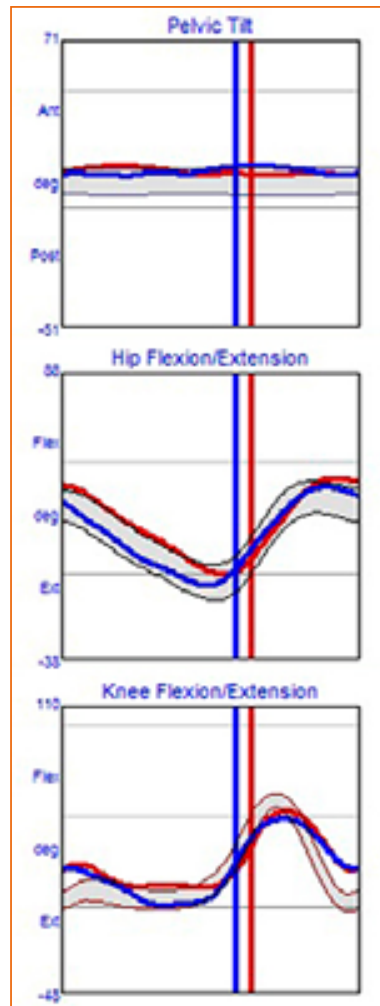

Anide Dorsiplantar

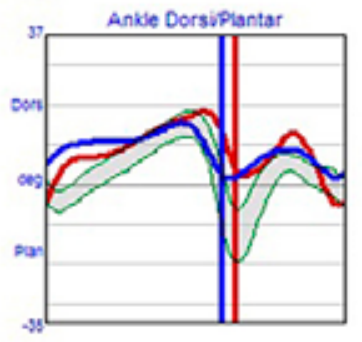

Şekil 1. Dinamik kinematik grafikler.
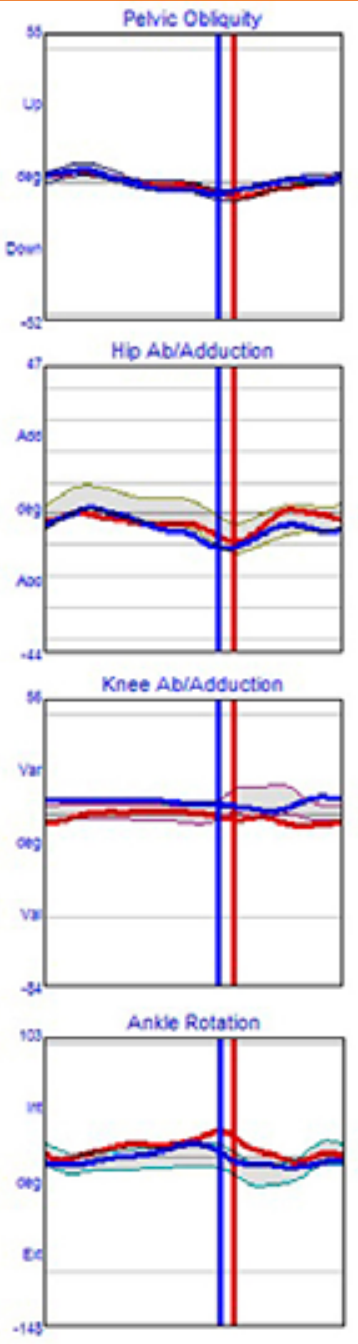

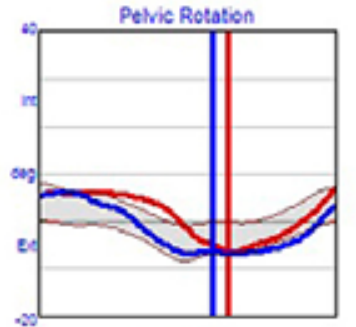

Hip Rotation

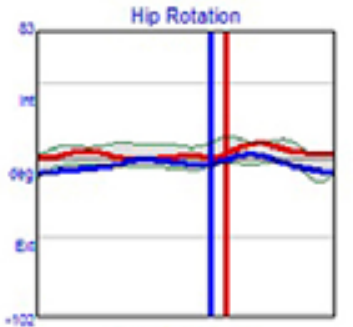

Knee Rotation

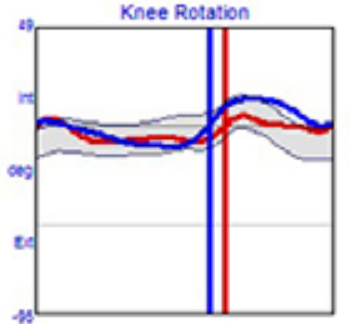

Foot Progress Angles

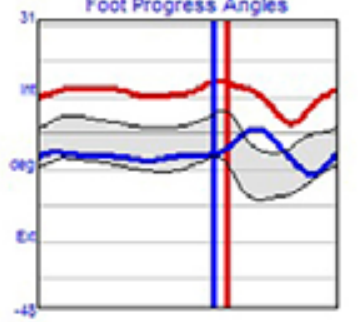

\section{Pedobarografi}

Yürüme analizi değerlendirmesi sırasında pedobarografik verilerin de değerlendirilmesi mümkündür. $\mathrm{Bu}$ sayede basma fazında ayağın zemin ile teması sırasında oluşan plantar yük dağılımı değerlendirilebilmekte$\operatorname{dir}$ (Şekil 4).

\section{Enerji Tüketimi}

Enerji tüketimi, hastanın kendini rahat hissettiği bir hızda yürümesi sırasında, oksijen tüketimi, karbondioksit üretimi ve kalp hızı ölçülerek hesaplanır. Enerji tüketiminin yürüme verimliliği ile ters bir ilişkisi olduğu bilinmektedir. Bu yüzden enerji tüketimi, yürümenin verimliliği veya bir sonuç belirteci olarak kullanılabilir. ${ }^{[5]}$

\section{SEREBRAL PALSILI HASTALARDA GÖZLENEN YÜRÜME TIPLERi}

SP'de, geniş bir çeşitlilikte yürüme değişiklikleri gözlenebilir. Benzer yürüme tiplerinin bir arada gruplandırılması, iletişimi rahatlatsa da aslında geniş bir yürüme spektrumunun basitleştirilmesine neden olur. ${ }^{[26]}$ SP'li bir hastada, birden farklı yürüme tipine geçiş gözlenebilir. Bazı yürüme tipleri ve kombinasyonları sınıflandırmalarda belirtilmez. ${ }^{[7]}$ Bu nedenle SP'de görülen yürüme tiplerinin yanı sıra sık gözlenen spesifik yürüme değişiklikleri de bilinmelidir.

SP'de gözlenen yürüme tiplerinin sınıflandırmasında sıklıkla çift veya tek taraflı tutulum olmasına göre ayrı sınıflandırma yapılır. Birçok sınıflandırma sagittal kinematiklerin gözlemine dayanır. 


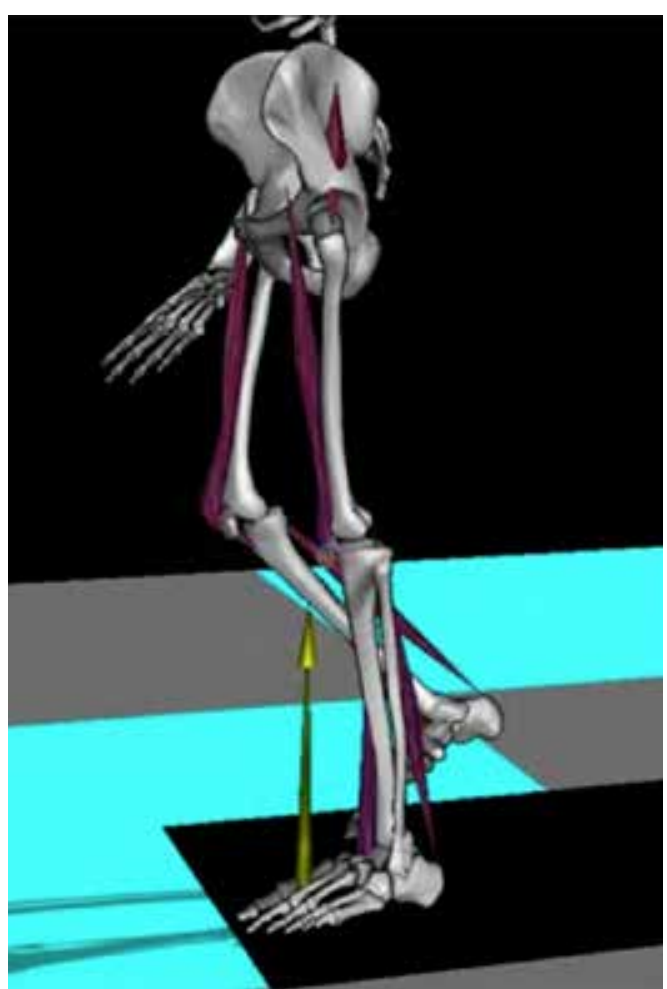

Şekil 2. Kuvvet plağı sayesinde elde edilen yer tepkime vektörü (sarı ok).
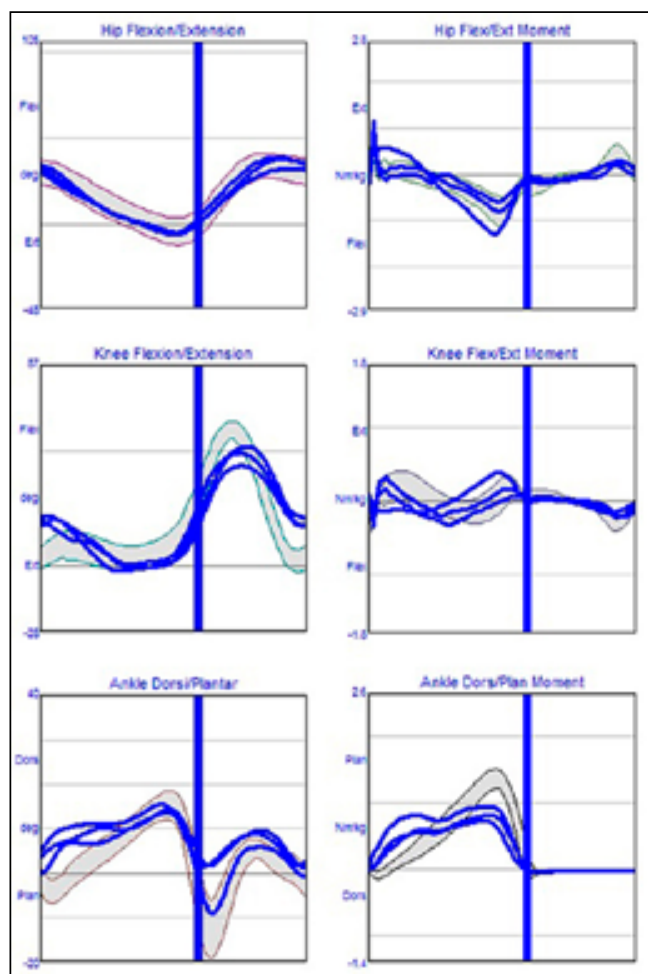

Knoe FievExc Homent
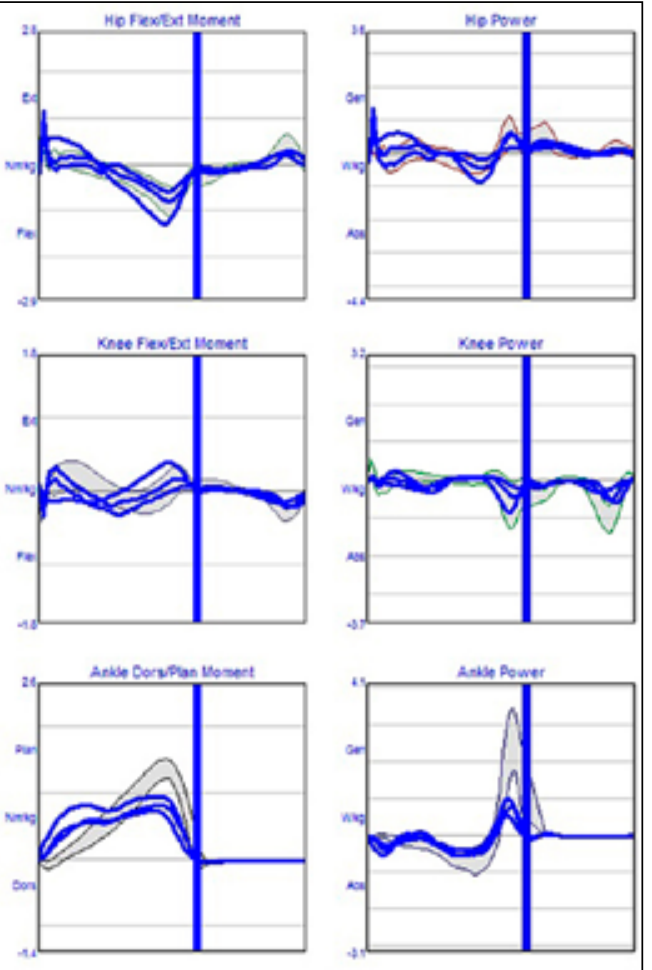

Şekil 3. Diz, kalça ve ayak bileğinin sağdan sola, kinematik, moment ve güç grafikleri.

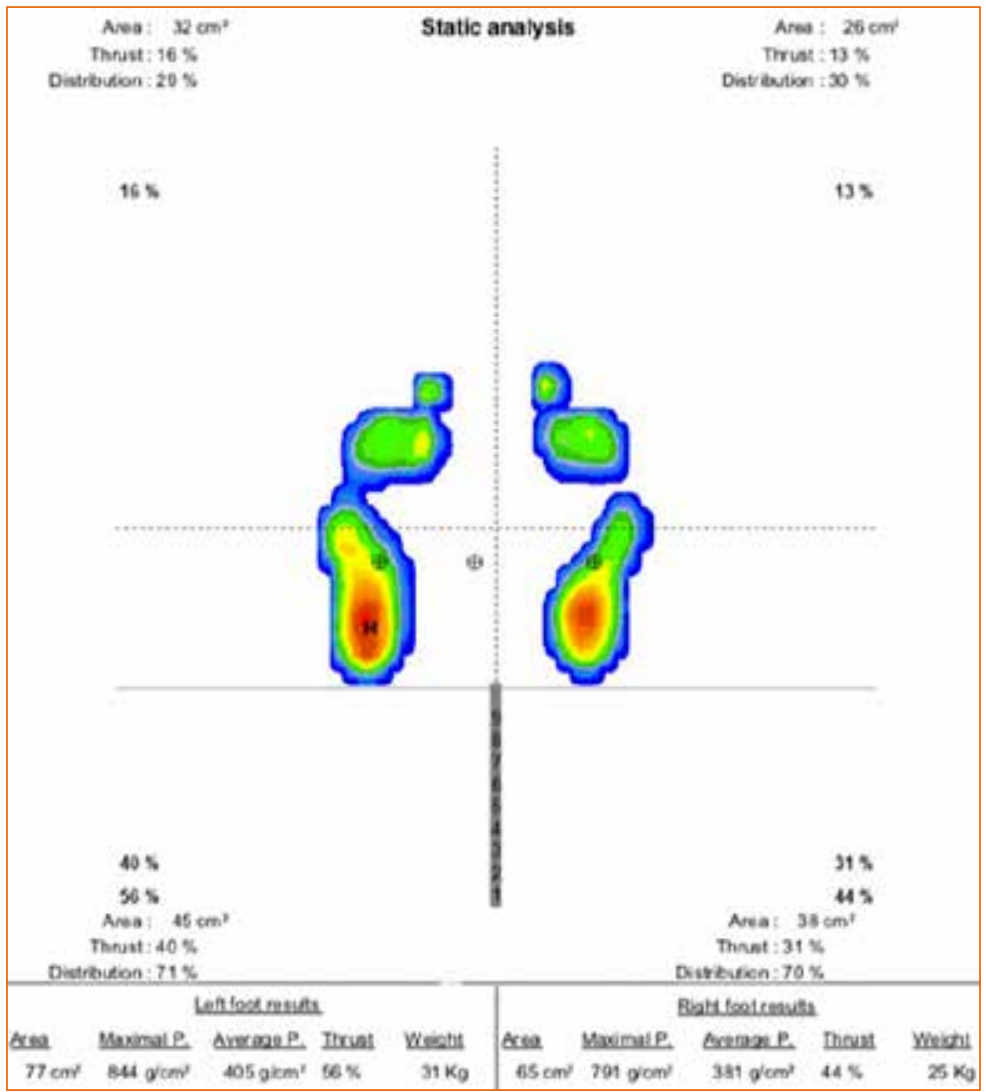

Şekil 4. Statik pedobarografik görüntü. 


\section{Tek Taraflı Spastik SP Yürüme Tipleri}

Tek taraflı spastik serebral palsi için ilk sınıflandırma Winters ve ark. tarafindan yapılmıştır. ${ }^{[27]}$ Rodda ve Graham, dizde hiperekstansiyonu ve kalçada transvers plan kayması olan olguları da ekleyerek sınıflandırmayı genişletmiştir. ${ }^{[28]}$ Bu sınıflara ait yürüme tipleri aşağıda anlatılmıştır (Şekil 5)

\section{Tip 1 hemipleji}

Salınım fazında daha belirgin gözlenen ve ayak bileği dorsifleksörlerinin bu fazda selektif kontrol kaybına bağlı oluşan düşük ayak yürüyüşü vardır. Baldır kaslarında kontraktür yoktur. Dolayısıyla basma fazı boyunca ayak bileği dorsifleksiyonu göreceli olarak normaldir. Bu tutulum seviyesindeki hastalar daha önceden Aşil gevşetme müdahalesi yapılmadığı durumlarda çok nadir görülür.

\section{Tip 2 hemipleji}

Klinik pratikte en sık gözlenen hemipleji tipidir. Gastrosoleus kasının spastisitesi veya kontraktürü nedeni ile basma fazında ayak bileğinde gerçek ekin deformitesi gözlenir. Ayak bileği ekstansör ve tibialis anterior kaslarının güçsüzlüğü nedeni ile salınım fazında dorsifleksiyonda yetersizlik gözlenebilir. Gerçek ekinus deformitesi gözlendiği zaman ayak bileği tüm basma fazı boyunca plantar fleksiyonda kalmaktadır. Plantar fleksiyon - diz ekstansiyon çiftlenmesi aşırı aktif olabilir ve bu nedenle dizde, ekstansiyon veya rekurvasyon pozisyonu gelişebilir. ${ }^{[29]}$

\section{Tip 3 hemipleji}

Tip 3 hemipleji gastrosoleus spastisitesi veya kontraktürü, salınım fazında ayak bileği dorsifleksiyon kaybı ve hamstring/kuadriseps ko-kontraksiyonunun sonucu olarak fleksiyonda, sert diz yürüyüşü ile karakterizedir.

\section{Tip 4 hemipleji}

Spastik diplejiklerde olduğu gibi daha fazla proksimal kas grubu tutulumu gözlenir. Fakat, tutulum tek taraflı olduğundan, pelvik retraksiyonu da içerek şekilde iki taraf arasında belirgin bir asimetri vardır. Sagittal planda ekin, fleksiyonda sert diz, fleksiyonda kalça ve artmış anterior pelvik tilt gözlenir. Koronal planda, kalça adduksiyonu ve transvers planda iç rotasyonu vardır. Bu olgularda kalçanın subluksasyon insidansı artmıştır ve eklemin radyolojik incelemesi mutlaka yapılmalıdır. ${ }^{[30]}$

\section{Çift Taraflı Spastik Serebral Palsi Yürüme Tipleri}

Sutherland'in [31] dizin yürüme farklılıklarının sınıflandırmasına dayanarak, Rodda ve Graham ${ }^{[28]}$, ayak bileği, diz, kalça ve pelvisin sagittal kinematiklerine göre sınıflandırma öne sürmüşlerdir. Buna göre dört ana grup belirlenmiştir: gerçek ekin, sıçrama yürüyüşü, görünür ekin ve çömelme yürüyüşü (Şekil 6).

\section{Gerçek ekin}

Diplejik SP'li bir çocuk destekli veya desteksiz yürümeye başladığı zaman baskın olan baldır kaslarının spastisitesi sonucu, basma fazı boyunca, diz ve kalça

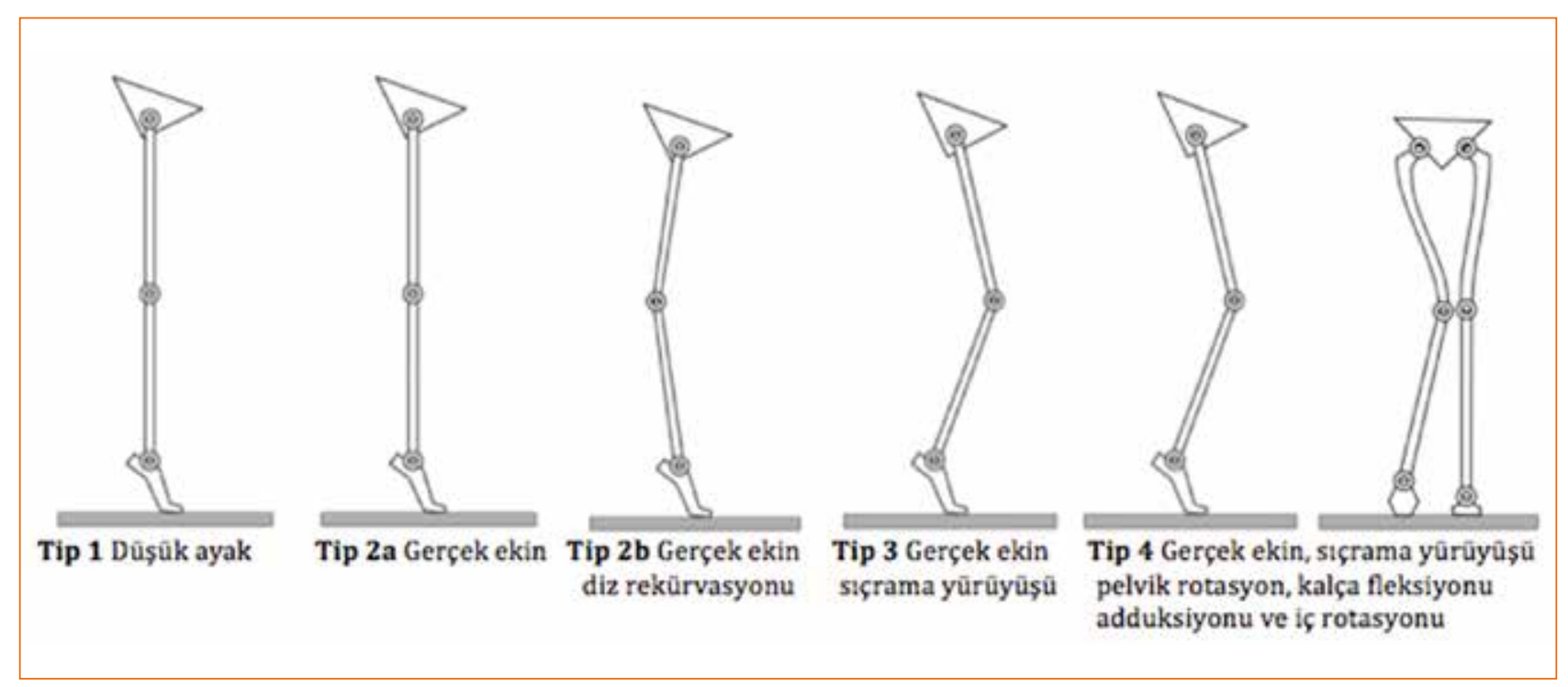

Şekil 5. Tek taraflı spastik SP yürüme tipleri. 
ekstansiyonda iken ayak bileği plantar fleksiyonda yürüyüş gözlenir. Bazen gerçek ekin deformitesi dizin rekurvasyona gitmesi ile saklanabilir. Bu yürüme paterninin devamlılığı nadir olup sıklıkla spinal lezyona sekonder gelişen spastisitesi olan çocuklarda (örn; herediter spastik paraparezi) gözlenir.

\section{Sıçrama yürüyüşü}

Sıçrama yürüyüşü, özellikle baldır spastisitesi ile beraber daha proksimal (kalça ve diz eklemi) tutulumu olan diplejik çocuklarda gözlenir. Ayak bileği ekinde, kalça ve diz fleksiyondadır, pelvisin anterior tilti ve lomber lordoz artmıştır. Salınım fazında rektus femoris aktivitesine bağlı sert diz sıklıkla gözlenir.

\section{Görünür ekin}

Çocuk büyüdükçe ve ağırlaştıkça, baldır kaslarını etkileyen ve ayak bileği plantar fleksiyon diz ekstansiyon çiftlenmesini daha az etkili kılan değişiklikler gelişir. Zamanla ekin azalırken, kalça ve diz fleksiyonu artar. Böylece görünür ekin denilen, görsel yürümede parmak ucu yürümenin gözlendiği; ama üç boyutlu yürüme analizinde, sagittal plan kinematiklerinde basma fazı boyunca diz ve kalça eklemi artmış fleksiyonda iken ayak bileğinin normal dorsifleksiyon hareket genişliğinde olduğu yürüme şekli gözlenmeye başlar. Bu noktada gastrosoleusun daha zayıflatılması (botoks veya cerrahi müdahale) çömelme yürüyüşüne geçişe neden olabilir. Tedavi değerlendirmesinde daha proksimal seviyeler göz önünde bulundurulmalıdır. ${ }^{[28,32]}$

\section{Çömelme yürüyüşü}

Çömelme yürüyüşü ayak bileğinde pes kalkaneus veya artmış dorsifleksiyon ile beraber kalça ve diz ekleminin artmış fleksiyonudur. Bu yürüme şekli ağır tutulumlu diplejik serebral palsi veya kuadriplejik SP'li olguların çoğunda görülür. Maalesef spastik diplejik olguların çoğunun çömelme yürüyüşünün altında gastrosoleus kasının küçük yaştaki çocuklarda izole gevşetilmesi saptanmıştır. ${ }^{[32]}$ Aşil tendonu bir kez uzatıldıktan sonra, hamstring ve iliopsoas spastisitesi fark edilmez ise, kalça ve diz fleksiyonunda hızlı bir artış gözlenir. Bu enerji tüketiminin arttığı, adolesan çağda sıklıkla diz önü ağrısı ve patellar sorunlara yol açan yürüyüşe sahip olmaya neden olur.

Bu basit sınıflandırmalar özellikle sagittal plan patolojilerine konsantre olmaktadır. Spastik diplejik çocukların birçoğunda koronal ve transvers plan bozuklukları da bulunur. Koronal plan bozukluklarına örnek olarak, kalça adduksiyon spastisitesi veya kontraktürü, alt ekstremite eşitsizliği, kalça subluksasyonu verilebilir.

Transvers plan problemleri, görsel olarak değerlendirilmesi en zor olup, üç boyutlu yürüme analizi ile değerlendirmek yararlıdır. ${ }^{[28]} \mathrm{Bu}$ plandaki torsiyonel deformiteler, kaldıraç kolu hastalığına (lever arm disease) neden olmakta ve kasların verimli çalışmasını etkilemektedir. ${ }^{[33]}$ Diplejik hastalarda en sık gözlenen transvers plan bozuklukları, artmış femoral anteversiyon, tibial eksternal torsiyon, ayak ortası kırılması, topuk valgusu ve abduksiyondur.

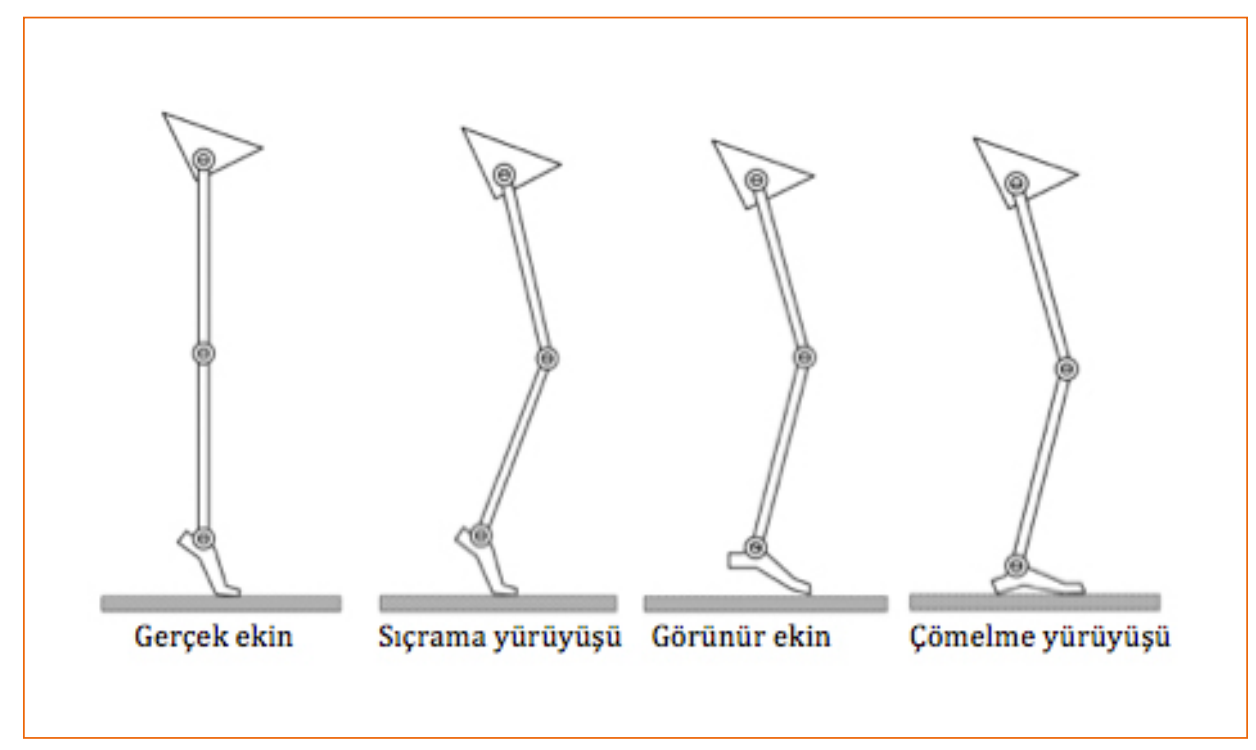

Şekil 6. Çift taraflı spastik SP yürüme tipleri. 


\section{SEREBRAL PALSIDE SPESIFIK YÜRÜME DEVIYASYONLARI}

Her SP'li olgu kendine özgü, birçok hareket kaybı oluşturacak etkilenimin, değişik ve hatta her iki ekstremitede bile farklı seviyede gözlenebilecek düzeyde tutulumuna sahip olabilir. SP'de gözlenen yürüme sapmalarının daha iyi anlaşılması için Armand ve ark., her eklem/segment planının sapmalarını ve bunun etkilerini gösteren kinematik yürüme değişikliklerini özetlemişlerdir. ${ }^{[7]}$ Daha önce Perry tarafından da bahsedilmiş olan ve burada özetlenen birçok yürüme bozukluğunun çıkarımlarının kanıttan çok tecrübeye dayandığını belirtmişlerdir. Yürüme bozukluklarının değerlendirilmesinde yardımcı olan kinetik grafiler, EMG ve diğer yardımcı modaliteleri kullanmış olmasalar bile SP'li olguların yürüme analizinde gözlenen yürüme şekli değişikliklerinin anlaşılmasında temel oluşturan bir tablo sunmuşlardır (Tablo 3 ).
Üç boyutlu yürüme analizi, yürümenin değerlendirilmesinde ve daha ayrıntılı incelenmesinde gün geçtikçe önem kazanmaktadır. Birçok çalışma, SP'li hastaların, aynı laboratuvarda farklı seferlerde değerlendirilmelerinin yeterli oranda güvenilirliğe sahip olduğunu göstermiştir. ${ }^{[34]}$ Fakat, farklı laboratuvarlarda, farklı tutulum seviyesindeki hastaların değerlendirilmeleri arasındaki güvenilirlik ile ilgili çalışmalara ait çıkarımlar yetersizdir. Günümüzde bazı kanıtlar, yürüme analizi ile değerlendirme sonrası tedavi karar çeşitliliğinin daha net olduğunu gösterse de, yürüme analizi yapılan veya yapılmayan hastaların tedavi sonuçlarının karşılaştırılmasında hangi grupta üstünlük olduğuna dair güvenilir bir çalışma bulunmamaktadır. ${ }^{[34]}$ Üंç boyutlu yürüme analizi teknolojisinin daha da ilerlemesi, klinik kullanımdaki yerinin artmasına ve kanıta dayalı tedavide objektif sonuçların toplanmasına yardımcı olacaktır.

Tablo 3. Yürüme analizindeki kinematik deviyasyonlar

\begin{tabular}{|c|c|c|c|}
\hline $\begin{array}{l}\text { Yürüme } \\
\text { deviyasyonu* }\end{array}$ & Tanım & $\begin{array}{l}\text { Sorunun nedeni (-) ve destekleyen diğer } \\
\text { yürüme analizi verisi (+) }\end{array}$ & $\begin{array}{l}\text { Karışıklık yaratabilecek } \\
\text { faktör }\end{array}$ \\
\hline & $\begin{array}{l}\text { Eksternal ayak ilerleme } \\
\text { açısı }\end{array}$ & $\begin{array}{l}\text { - Artmış eksternal tibial torsiyon } \\
\text { - Ayak deformitesi } \\
\text { + Artmış ayak bileği eksternal rotasyonu }\end{array}$ & $\begin{array}{l}\text { - Uzamış pelvik retraksiyon } \\
\text { - Artmış kalça dış rotasyonu }\end{array}$ \\
\hline & $\begin{array}{l}\text { İnternal ayak ilerleme } \\
\text { açısı }\end{array}$ & $\begin{array}{l}\text { - Artmış femoral anteversiyon } \\
\text { + Artmış kalça iç rotasyonu } \\
\text { - Azalmış eksternal tibial torsiyon } \\
\text { - Ayak deformitesi } \\
\text { + Artmış ayak bileği iç rotasyonu }\end{array}$ & - Uzamış pelvik protraksiyon \\
\hline & $\begin{array}{l}\text { Ayak bileği ilk } \\
\text { yuvarlanma kaybı }\end{array}$ & $\begin{array}{l}\text { - Ayak bileği dorsifleksör güçsüzlüğğ veya azalmış selektif motor kontrol } \\
\text { + Salınımda artmış plantar fleksiyon } \\
\text { - Plantar fleksör kontraktürü veya aşıı aktivitesi } \\
\text { + Tüm fazlarda artmış plantar fleksiyon }\end{array}$ & - Ekstremite uzunluk eşitsizliği \\
\hline & $\begin{array}{l}\text { Erken ayak bileği } \\
\text { plantar fleksiyonu } \\
\text { (erken basma fazı) }\end{array}$ & $\begin{array}{l}\text { - Plantar fleksör aşırı aktivitesi } \\
\text { + Prematür diz ekstansiyonu/hiperekstansiyonu }\end{array}$ & $\begin{array}{l}\text { - Ekstremite eşitsizliği veya karşı ayağın } \\
\text { yerle temasının kesilmesinde problem } \\
\text { - Artmış diz fleksiyonu }\end{array}$ \\
\hline & $\begin{array}{l}\text { Yetersiz ayak bileği } \\
\text { dorsifleksiyonu }\end{array}$ & - Plantar fleksör kontraktürü veya aşırı aktivitesi & \\
\hline & $\begin{array}{l}\text { Artmıs ayak bileği } \\
\text { dorsifleksiyonu }\end{array}$ & $\begin{array}{l}\text { - Soleus güçsüzlüğğ veya artmış kas uzunluğu } \\
\text { + Basma ortasında artmış diz fleksiyonu }\end{array}$ & \\
\hline & Artmış diz fleksiyonu & $\begin{array}{l}\text { - Hamstring assırı aktivitesi } \\
\text { - Plantar fleksör kontraktürü veya aşırı aktivitesi } \\
\text { + Artmış ayak bileği plantar fleksiyonu }\end{array}$ & \\
\hline
\end{tabular}


Tablo 3. Yürüme analizindeki kinematik deviyasyonlar (devam)

\begin{tabular}{|c|c|c|c|}
\hline $\begin{array}{l}\text { Yürüme } \\
\text { deviyasyonu* }\end{array}$ & Tanım & $\begin{array}{l}\text { Sorunun nedeni (-) ve destekleyen diğer } \\
\text { yürüme analizi verisi }(+)\end{array}$ & $\begin{array}{l}\text { Karışıklık yaratabilecek } \\
\text { faktör }\end{array}$ \\
\hline & $\begin{array}{l}\text { Basma ortası azalmış } \\
\text { diz ekstansiyonu }\end{array}$ & $\begin{array}{l}\text { - Hamstring kontraktürü veya aşııı aktivitesi } \\
\text { - Fikss diz fleksiyon deformitesi } \\
\text { - Kalça veya diz ekstansör güçsüzlüğü } \\
\text { + Artmış kalça fleksiyonu } \\
\text { - Ayak bileği plantar fleksör güçsüzlüğğü } \\
\text { + Artmış ayak bileği dorsifleksiyonu } \\
\text { - Artmış ayak bileği plantar fleksör aktivitesi veya kontraktürü } \\
\text { + Artmış ayak bileği plantar fleksiyonu }\end{array}$ & $\begin{array}{l}\text { - Diğer planlarla olan etkileşim } \\
\text { (transvers-sagittal) } \\
\text { + Eksternal tibial torisyon } \\
\text { + Artmış femoral anteversiyon } \\
\text { + Ayak deformitesi }\end{array}$ \\
\hline & $\begin{array}{l}\text { Salınımda azalmış } \\
\text { veya gecikmiş diz } \\
\text { fleksiyonu }\end{array}$ & $\begin{array}{l}\text { - Rektus femoris aşııı aktivitesi } \\
\text { + Geç basma veya erken salınım fazında rektus femoris aktivitesi } \\
\text { - Sert diz yürüyüşü, hamstring/rektus ko-kontraksiyonu }\end{array}$ & $\begin{array}{l}\text { - Diğer planlarla olan etkilessim (transvers- } \\
\text { sagittal) eğer pelvis retraksiyonu ve kalça } \\
\text { eksternal rotasyonu varsa } \\
\text { - Ayak bileği üçüncü yuvarlanma fazında } \\
\text { azalmış itme } \\
\text { - Azalmış hız }\end{array}$ \\
\hline & $\begin{array}{l}\text { Yüklenme kabulünde } \\
\text { azalmış diz fleksiyonu }\end{array}$ & $\begin{array}{l}\text { - Kuadriseps güçsüzlüğğ veya patella ağrısı } \\
\text { + Basma fazında azalmış diz ekstansiyon momenti }\end{array}$ & \\
\hline & $\begin{array}{l}\text { Basma ortası diz } \\
\text { hiperekstansiyonu }\end{array}$ & $\begin{array}{l}\text { - Kuadriseps güçsüzlüğg̈ } \\
\text { - Plantar fleksör kontraktürü veya aşırı aktivitesi } \\
\text { + Artmış ayak bileği plantar fleksiyonu }\end{array}$ & \\
\hline & $\begin{array}{l}\text { Artmış kalça } \\
\text { fleksiyonu }\end{array}$ & $\begin{array}{l}\text { - Kalça fleksiyon kontraktürü veya aşırı aktivitesi } \\
\text { + Anterior pelvik tilt, çift hörgüç } \\
\text { - Kalça ekstansör zayıflığı }\end{array}$ & $\begin{array}{l}\text { - Uzamış anterior pelvik tilt } \\
\text { - Assırı diz fleksiyonu } \\
\text { - Ekstremite eşitsizliggi }\end{array}$ \\
\hline & $\begin{array}{l}\text { Kalça ekstansiyon } \\
\text { kaybi }\end{array}$ & $\begin{array}{l}\text { - Kalça fleksiyon kontraktürü veya aşıı aktivitesi } \\
\text { + Anterior pelvik tilt, çift hörgüç̧ } \\
\text { - Azalmı̧ kalça hareket açıklığı } \\
\text { + Anterior pelvik tilt, tek hörgüç }\end{array}$ & - Ekstremite eşitsizliği \\
\hline & $\begin{array}{l}\text { Basma fazı artmış } \\
\text { kalça adduksiyonu }\end{array}$ & $\begin{array}{l}\text { - Kalça abduktor zayıflığı } \\
\text { + Kontrlateral pelvisde düsme } \\
\text { - Kalça adduktor kontraktürü veya aşırı aktivitesi }\end{array}$ & $\begin{array}{l}\text { - Artmış kalça iç rotasyonu } \\
\text { - Pelvik retraksiyon veya oblisite } \\
\text { - Ekstremite eşitsizliği }\end{array}$ \\
\hline & $\begin{array}{l}\text { Artmış kalça iç } \\
\text { rotasyonu }\end{array}$ & $\begin{array}{l}\text { - Artmış femur boyun anteversiyonu } \\
\text { - Artmış tibial eksternal torsiyon }\end{array}$ & - Aynı tarafda pelvik retraksiyon \\
\hline & $\begin{array}{l}\text { Artmış kalça dış } \\
\text { rotasyonu }\end{array}$ & $\begin{array}{l}\text { - Azalmış femur anteversiyonu } \\
\text { - Azalmış external tibial torsiyon }\end{array}$ & $\begin{array}{l}\text { - Aynı tarafta pelvik protraksiyon } \\
\text { - Obezite/genişuyluk } \\
\text { - Ayak deformitesi }\end{array}$ \\
\hline & Pelvik tilt çift hörgüç & $\begin{array}{l}\text { - Kalça fleksiyon kontraktürü veya aşırı aktivitesi } \\
\text { + Azalmış kalça ekstansiyonu }\end{array}$ & \\
\hline & $\begin{array}{l}\text { Pelvik oblisite yukarı } \\
\text { veya aşağı }\end{array}$ & $\begin{array}{l}\text { - Alt ekstremite eşitsizliği } \\
\text { + Aşır kalça abduksiyonu } \\
\text { - Adduksiyon kontraktürü }\end{array}$ & $\begin{array}{l}\text { - Skolyoz } \\
\text { - Hemipleji }\end{array}$ \\
\hline & $\begin{array}{l}\text { Ters pelvik rotasyon } \\
\text { profili }\end{array}$ & $\begin{array}{l}\text { - Genel güçsüzlük } \\
\text { + Ters kalça adduksiyon profili }\end{array}$ & \\
\hline & $\begin{array}{l}\text { Uzamıss pelvik pro veya } \\
\text { retraksiyon }\end{array}$ & - Genel güçsüzlükte asimetri & $\begin{array}{l}\text { - Femoral torsiyon deformitesi } \\
\text { - Tibial torsiyon deformitesi } \\
\text { - Hemipleji }\end{array}$ \\
\hline
\end{tabular}

* Gri, normal popülasyondan oluşturulmuş yürüme paternini, kırmızı ise incelenen yürüme analizi deviyasyonunu göstermektedir. 


\section{KAYNAKLAR}

1. Himmelmann K, Hagberg G, Uvebrant P. The changing panorama of cerebral palsy in Sweden. X. Prevalence and origin in the birth-year period 1999-2002. Acta Paediatr 2010;99(9):1337-43. Crossref

2. Serdaroglu A, Cansu A, Ozkan S, Tezcan S. Prevalence of cerebral palsy in Turkish children between the ages of 2 and 16 years. Dev Med Child Neurol 2006;48(6):413-6. Crossref

3. Hutton JL, Colver AF, Mackie PC. Effect of severity of disability on survival in north east England cerebral palsy cohort. Arch Dis Child 2000;83(6):468-74. Crossref

4. Palisano R, Rosenbaum P, Walter S, Russell D, Wood E, Galuppi B. Development and reliability of a system to classify gross motor function in children with cerebral palsy. Dev Med Child Neurol 1997;39(4):214-23. Crossref

5. Feng J, Wick J, Bompiani E, Aiona M. Applications of gait analysis in pediatric orthopaedics. Curr Orthop Pract 2016;27(4):455-64. Crossref

6. Perry J. Normal and pathological gait. In: Bunch WH, editor. Atlas of Orthotics, 2nd ed. St Louis MI: C. V. Mosby; 1985. pp.76-111.

7. Armand S, Decoulon G, Bonnefoy-Mazure A. Gait analysis in children with cerebral palsy. EFORT Open Rev 2016;1(12):448-60. Crossref

8. Moissenet M, Armand S. Qualitative and quantitative methods of assessing gait disorders. In: Canavese F, Deslandes J, editors. Orthopedic Management of Children with Cerebral Palsy: A Comprehensive Approach. New York: Nova Science Publishers Inc.; 2015. pp.215-39.

9. Toro B, Nester C, Farren P. A review of observational gait assessment in clinical practice. Physiother Theory Pract 2003;19(3):137-49. Crossref

10. Kawamura CM, de Morais Filho MC, Barreto MM, de Paula Asa SK, Juliano Y, Novo NF. Comparison between visual and three-dimensional gait analysis in patients with spastic diplegic cerebral palsy. Gait Posture 2007;25(1):18-24. Crossref

11. Toro B, Nester CJ, Farren PC. The development and validity of the Salford Gait Tool: an observation-based clinical gait assessment tool. Arch Phys Med Rehabil 2007;88(3):321-7. Crossref

12. Read HS, Hazlewood ME, Hillman SJ, Prescott RJ, Robb JE. Edinburgh visual gait score for use in cerebral palsy. J Pediatr Orthop 2003;23(3):296-301. Crossref

13. Mackey AH, Lobb GL, Walt SE, Stott NS. Reliability and validity of the Observational Gait Scale in children with spastic diplegia. Dev Med Child Neurol 2003;45(1):4-11. Crossref

14. Wren TA, Rethlefsen SA, Healy BS, Do KP, Dennis SW, Kay RM. Reliability and validity of visual assessments of gait using a modified physician rating scale for crouch and foot contact. J Pediatr Orthop 2005;25(5):646-50. Crossref

15. Brown CR, Hillman SJ, Richardson AM, Herman JL, Robb JE. Reliability and validity of the Visual Gait Assessment Scale for children with hemiplegic cerebral palsy when used by experienced and inexperienced observers. Gait Posture 2008;27(4):648-52. Crossref

16. Rathinam C, Bateman A, Peirson J, Skinner J. Observational gait assessment tools in paediatrics -a systematic review. Gait Posture 2014;40(2):279-85. Crossref
17. Hislop HJ, Montgomery J, Connolly BH, Daniels L. Daniels and Worthingham's Muscle Testing: Techniques of Manual Examination, 6th ed. Philadelphia: W. B. Saunders Company; 1995.

18. Bohannon RW, Smith MB. Interrater reliability of a modified Ashworth scale of muscle spasticity. Phys Ther 1987;67(2):206-7. Crossref

19. Graham HK, Harvey A, Rodda J, Nattrass GR, Pirpiris M. The Functional Mobility Scale (FMS). J Pediatr Orthop 2004;24(5):514-20. Crossref

20. Baker R. Gait analysis methods in rehabilitation. J Neuroeng Rehabil 2006;3:4. Crossref

21. Baker R, McGinley JL, Schwartz MH, Beynon S, Rozumalski A, Graham HK, Tirosh O. The gait profile score and movement analysis profile. Gait Posture 2009;30(3):265-9. Crossref

22. Schwartz MH, Rozumalski A. The Gait Deviation Index: a new comprehensive index of gait pathology. Gait Posture 2008;28(3):351-7. Crossref

23. Winter DA. Biomechanics of human movement with applications to the study of human locomotion. Crit Rev Biomed Eng 1984;9(4):287-314.

24. Davis RB. Reflections on clinical gait analysis. J Electromyogr Kinesiol 1997;7(4):251-7. Crossref

25. Hermens HJ, Freriks B, Disselhorst-Klug C, Rau G. Development of recommendations for SEMG sensors and sensor placement procedures. J Electromyogr Kinesiol 2000;10(5):361-74. Crossref

26. Dobson F, Morris ME, Baker R, Graham HK. Gait classification in children with cerebral palsy: a systematic review. Gait Posture 2007;25(1):140-52. Crossref

27. Winters TF Jr, Gage JR, Hicks R. Gait patterns in spastic hemiplegia in children and young adults. J Bone Joint Surg Am 1987;69(3):437-41. Crossref

28. Rodda J, Graham HK. Classification of gait patterns in spastic hemiplegia and spastic diplegia: a basis for a management algorithm. Eur J Neurol 2001;8(Suppl 5):98-108. Crossref

29. Boyd R, Graham HK. Botulinum toxin A in the management of children with cerebral palsy: indications and outcome. Eur J Neurol 1997;4(Suppl 2):S15-21.

30. Abousamra O, Er MS, Rogers KJ, Nishnianidze T, Dabney KW, Miller F. Hip Reconstruction in Children with Unilateral Cerebral Palsy and Hip Dysplasia. J Pediatr Orthop 2016;36(8):834-40. Crossref

31. Sutherland DH, Davids JR. Common gait abnormalities of the knee in cerebral palsy. Clin Orthop Relat Res 1993;(288):13947. Crossref

32. Borton DC, Walker K, Pirpiris M, Nattrass GR, Graham HK. Isolated calf lengthening in cerebral palsy. Outcome analysis of risk factors. J Bone Joint Surg Br 2001;83-B(3):364-70. Crossref

33. Rethlefsen SA, Kay RM. Transverse plane gait problems in children with cerebral palsy. J Pediatr Orthop 2013;33(4):42230. Crossref

34. Theologis T, Wright J. Is 3-D gait analysis essential? By Professor James Wright: Introduction by Mr. Tim Theologis. Gait Posture 2015;42(3):227-9. Crossref 